\title{
Algorithmic Trading in Volatile Markets
}

\author{
Hao Zhou, Petko S. Kalev* and Guanghua (Andy) Lian ${ }^{\dagger}$ \\ School of Commerce, University of South Australia, Australia
}

May 16, 2014

\begin{abstract}
This paper considers algorithmic trading (AT) during the most volatile trading days on the Australian Securities Exchange from October 2008 till October 2009. We show a significant negative association between the level of AT activities in a particular stock and the stock's price swings. We observe that algorithmic traders closely monitor volume-weighted average prices in their execution strategies. We also provide strong evidence that the order imbalances of algorithmic traders have a smaller impact on the abnormal returns of individual stocks compared to order imbalances based on non-algorithmic trading.
\end{abstract}

Keywords: Algorithmic trading; Order imbalance; Volatile markets; Volume-weighted average price; Trading volume

JEL classification: G12, G14, G19.

\footnotetext{
${ }^{*}$ Corresponding author: Petko Kalev, School of Commerce, University of South Australia Business School, University of South Australia, City West Campus, GPO Box 2471, Adelaide, South Australia 5001, Australia; tel: +61 883027122 ; fax: +61 8 8302 0992; e-mail: petko.kalev@unisa.edu.au.

${ }^{\dagger}$ We thank Terry Walter and seminar participants at the 25th Australasian Banking and Finance Conference for their valuable comments. All errors or omissions are our own.
} 


\section{Introduction}

Technological developments over the past decade have substantially increased the use of computer algorithms by equity investors. Algorithmic trading (AT) accounts for the majority of the trading volume in developed countries. In our sample of Australian Securities Exchange (ASX) stocks, more than two-thirds of the trades are initiated by algorithms. In light of the extremely volatile events such as 'flash crash †, academic researchers, market regulators, and finance practitioners are keen to understand the implications of AT in volatile markets. Does AT contribute to the stock price decline when there is a large market drop? If so, what property of AT is the cause? The answers are important since understanding the characteristics of AT in turbulent periods is essential to formulate appropriate policies to encourage or limit different aspects of AT. The current paper aims to address these issues.

Hendershott, Jones, and Menkveld (2011) find that, overall, AT plays a beneficial role in terms of liquidity and price discovery in rising markets. At the same time, the authors warn that investigations of the characteristics of AT 'in turbulent or declining markets' (p. 31) are equally important. We focus on the volatile days on the ASX from 27 October 2008 till 23 October 2009. Volatile days are defined as days when the absolute value of the market return exceeds 2\% (Dennis and Strickland, 2002). We employ a novel dataset in which each trade is flagged based on whether it is generated by a computer algorithm. The advantage of this dataset is that it enables us to identify AT without relying on proxies such as message traffic. In addition, for all transacted prices, we are able to distinguish the buy trades from the sell trades, which is crucial to the inference between AT and stock returns in our analysis.

While regulatory agencies have been expressing concerns about the implications of AT to long-term investor: ${ }^{2}$ until recently, most of the AT and high-frequency trading (HFT) ${ }^{3}$ studies have focused on ultra-short-term intraday effects ranging from milliseconds to minutes. For instance, Hendershott and Riordan (2014) relate AT to intraday liquidity measures such as the bid-ask spread and order book depth. Hasbrouck and Saar (2013) propose a

\footnotetext{
${ }^{1}$ On 6 May 2010, U.S. stock market indices and related securities experienced a sharp price drop of more than $5 \%$, only to recover in the course of about 30 minutes. See Kirilenko, Kyle, Samadi, and Tuzun (2011) for a detailed analysis.

${ }^{2}$ The Australian Securities Exchange (2010) mentions that bringing in new algorithmic traders (ATers) raises important public policy issues about balancing the interests of short-term traders with those of long-term investors. The U.S. Securities and Exchange Commission (2010) indicates that whether the market structural changes due to the ATers is better or worse for long-term investors is an important issue on which comment is requested.

${ }^{3} \mathrm{HFT}$, as a subset of AT, is generally distinguished from AT by its clear emphasis on the speed of trading.
} 
framework for identifying HFT and assess its intraday effects. Brogaard, Hendershott, and Riordan (2014) assess the impact of HFT on market qualities in second-by-second context and, more specifically, report the effect of HFT in the 20 seconds around public announcements. It is intuitive to analyse automated trading in ultra-high frequency since many of the proprietary trading strategies emphasize exploiting small and fleeting opportunities in the market. However, ultra-high frequency issues, such as whether prices adjust a fraction of a second faster, may not be the primary concern of long-term investors. There are reasons to suggest longer-term implications of AT. First, some ATers follow an extension of traditional trading strategies such as value, momentum, and pairs trading. These strategies often involve holding positions over days and longer horizons. Moreover, unlike in HFT, execution algorithms make up a significant portion of AT. These execution algorithms are services provided to buy-side clients to minimize the price impact of trading and thus the intention to trade is initially expressed by human traders. Therefore, the inference from these trades could be studied over horizons longer than a few minutes. More recently, longer-term effects of AT have been shown in the literature 5

In this paper, we investigate the empirical regularities of AT in turbulent markets. We use abnormal AT intensity to control for ATer's preference in certain stocks. This abnormal AT intensity is measured as the intensity of algorithmic trades on the event-day less the average AT intensity over previous five days. We find that, controlling for size, risk and liquidity, stocks traded more by AT, compared to nonAT, experience less downward price pressure when there is a broad market decline of more than two percent. Similar results are obtained on algorithmic buy trades when market is up by more than two percent. Specifically, the abnormal AT sell (buy) intensity in a stock is positively (negatively) related to the return of that stock on days when market experiences two percent or more declines (increases). Our findings are also economically significant, in which a ten percent increase in selling by ATers, on average, corresponds to twelve basis points increase in abnormal return for individual stocks in bear markets. Overall, our evidence suggests that, compared to nonalgorithmic trading (nonAT), AT does not contribute to price swing among individual stocks in volatile markets.

We also investigate the reasons for the empirical association between AT and price fluctuation. Hendershott

${ }^{4}$ Algorithms can be separated into execution algorithms and situational algorithms (Australian Securities Exchange, |2010). Execution algorithms seek to reduce the costs of executing large orders by minimizing the market impact of trades. In contrast, situational algorithms profit by monitoring and analysing market data and news. HFT is a subset of situational algorithms.

${ }^{5}$ For instance, Boehmer, Fong, and Wu (2012a) find that greater AT activity reduce a firm's net equity issues over the next year. Cumming, Zhan, and Aitken (2012) relate HFT to end-of-day manipulation on a monthly basis and argue that it curtails the frequency and severity of end-of-day manipulation. 
et al. (2011) suggest that execution algorithms can track the volume-weighted average price (VWAP) metric to reduce execution costs. The VWAP is the average price of each transaction over a certain time horizon (typically one day) weighted by the volume of each trade. The executed price of each trade can then be compared with the VWAP to evaluate the trade's execution performance 6 By monitoring the VWAP, ATers execute trades when the difference between the VWAP and the stock price becomes smaller. In the event of a large market-wide drop, ATers would be more patient in their trade execution and wait for the optimal VWAP-to-price relation. Therefore, ATers would be less likely to herd with nonATers. As a result, AT would smooth out the liquidity demand and would not contribute to further price declines. We find that, after controlling for market conditions, this is exactly the case. In particular, we estimate probit models of AT execution and show that ATers are more likely to trade when the difference between the stock price and the intraday VWAP at the time is small on market decline days, market rise days, and other days in our sample. This finding is consistent with the notion that ATers are more patient compared to nonATers and do not exacerbate the price pressure from the overall market.

In addition, we find significant return reversals following market decline days for stocks that have low AT activity. Specifically, stocks that have low AT activity tend to recover from their large event-day price drops in the subsequent five days. This result is important since large return declines associated with nonAT on event days could be caused by nonAT contributing to price discovery and the stocks traded by nonATers would adjust to their fundamental value more quickly. On the contrary, our findings on post-event day return reversals imply that nonAT is pushing stock prices over their fundamental value.

Our paper contributes to the literature in the following ways. First, we provide empirical evidence of the relation between AT and daily price fluctuations. To the best of our knowledge, this is the first study to investigate the impact of AT on daily stock returns. Hendershott et al. (2011) show that AT reduces the price impact of trades over the next five to 30 minutes. We differ in research design by focusing on turbulent periods and provide further complementary evidence. Our findings suggest some longer-term effects of AT, specifically, AT is negatively related to stock price swings on volatile days and the stock return reversal over the subsequent days.

Second, we provide explanations for the empirical relation between AT intensity and individual stock return fluctuations. Specifically, we investigate potential AT strategies that could affect daily returns. A number of

\footnotetext{
${ }^{6}$ The VWAP was first proposed by Berkowitz, Logue, and Noser $(1988)$. See Madhavan $(2002)$ for a comprehensive survey.
} 
studies have suggested that AT and HFT could follow VWAP strategies to optimize the timing of their trades (e.g. Domowitz and Yegerman 2005; Hendershott et al. 2011; Easley, Lopez de Prado, and O'Hara 2012). Carrion (2013) uses end-of-day VWAP metrics to show that, ex post, high-frequency traders time the market successfully. We differ from Carrion (2013) by using the intraday dynamic VWAP, which continuously updates throughout a trading session. We show that, ex ante, the execution decisions of algorithms are highly sensitive to the prevailing VWAP at the time of the trade.

Third, we contribute to the literature by empirically showing the difference between AT and nonAT order imbalances. A rich literature exists on the impact of order imbalances on stock markets (e.g. Hasbrouck and Seppi 2001; Chordia, Roll, and Subrahmanyam 2002; Chordia and Subrahmanyam 2004). We highlight the heterogeneity in the price impact of order imbalances from different investor groups. We find that nonAT order imbalances are more persistent compared to AT order imbalances; however, AT order imbalances have significantly less impact on stock returns. After controlling for trade size and the total level of trading activity, we find that, ceteris paribus, the impact of order imbalances by nonAT is $50 \%$ larger than by AT.

Finally, our findings about AT and price fluctuation complement the literature on AT and stock return volatility. The findings in the literature are divided. On one hand, AT could reduce volatility by mitigating market frictions, imperfect information, and transient liquidity mismatches. Theoretical work by Biais, Foucault, and Moinas (2013) predicts that, due to faster reactions and transaction speeds, HFT could speed up the price discovery process and enhance liquidity, which would in turn reduce volatility caused by non-informational trades. Hendershott and Riordan (2014) confirm that AT is able to quickly respond to price changes in futures market and adjust their positions in the spot market. They also find that ATers decrease uncertainty in liquidity provision and reduce risks associated with liquidity shortages. Brogaard et al. (2014) argue that high-frequency traders trade in the direction of permanent price movements and in the opposite direction of transitory pricing errors and thus contribute to the stability of the price discovery process in the stock market.

On the other hand, other studies argue that there is positive association between AT/HFT and volatility. Theoretical work by Martinez and Rosu (2013) models high-frequency traders as informed traders and shows that they generate most of the volatility and trading volume in the market. Boehmer, Fong, and $\mathrm{Wu}(2012 \mathrm{~b})$ find that AT increases volatility, especially on days when market making is difficult. Similarly, Zhang (2010) 
argues that HFT is positively correlated with stock price volatility and negatively related to the market's ability to incorporate new information. However, some of these studies could be inconclusive. First, the extent to which AT is informed remains an open question. For example, Frino, Viljoen, Wang, Westerholm, and Zheng (2014) show that nonAT is more informed than AT prior to earnings announcements and the opposite is true after the announcements. Brogaard et al. (2014) find that HFT has an informational advantage of up to three or four seconds. Second, proxies such as message traffic (Hendershott et al., 2011) could potentially cause noisy inference due to not being able to identify trade direction. Moreover, an increase in volatility alongside an observed increase in message traffic could only indicate an increase in the intensity of market activities. We show the importance of trade direction in assessing AT using AT transactions flagged by the ASX.

The rest of the study is organized as follows. Section 2 describes our data. Section 3 presents findings on AT volume ratios. Section 4 illustrates VWAP-tracking algorithms. Section 5 contains findings on order imbalances. Section 6 shows return reversal after event days. Finally, Section 7 concludes the paper.

\section{Data and Research Design}

We employ a novel AT dataset provided by the ASX. This dataset contains all algorithmic trades between 27 October 2008 and 23 October 2009. The sample period is approximately one calendar year, covering the Australian stock market around the peak of the global financial crisis. We believe it is an ideal sample to study trading characteristics in volatile markets since the majority of the days in the sample are within a high-volatility regime. Each trade contains the company code, trade price, trade volume, buy/sell indicator, time stamp to the nearest millisecond, and a special indicator for both sides of the transaction showing whether the trade is initiated by an ATer or nonATer. Similar to Hendershott and Riordan (2014), we merge the AT dataset with order-level data provided by the Securities Industry Research Centre of Asia-Pacific (SIRCA). The SIRCA data enable the accurate identification of buy/sell trades. This combination allows us to identify whether a trade was initiated by a buyer or a seller. as well as whether the trade was algorithm driven. The return of the All Ordinaries Index (All Ords) is acquired from Thompson Reuters' tick history.

Besides the ability to differentiate AT from nonAT transactions, the Australian data provide additional bene- 
fits. First, unlike many previous studies (e.g. Chordia et al. 2002) that rely on Lee and Ready's algorithm (1991), we use the 'true 7 classification of buys and sells from order-level data provided by the SIRCA. Ellis, Michaely, and O'Hara (2000) and Chakrabarty, Moulton, and Shkilko (2012) find the accuracy of Lee and Ready's algorithm to be $81.05 \%$ and $69 \%$, respectively. In the ASX, Aitken and Frino (1996) document the accuracy to be $74 \%$. Therefore, there is significant benefit in identifying the trade initiator with greater precision. Our data include all orders in the limit order book and identify their trade initiators based on their time priorities. Additionally, Dennis and Strickland (2002) use quarterly sampled corporate filing data to identify the participation rate of each investor group. We utilize the real-time transaction-level data, which enables us to better analyse the time series of investor participation and account for potential autoregressive properties.

We analyse how individual stock returns are correlated with the level of AT activity on volatile days. Similar to Dennis and Strickland (2002), we define volatile days as days when the absolute values of the returns on the market are greater than $2 \%$. We use the All Ords as our proxy for market returns. The All Ords contains the top 500 Australian ordinary stocks and amounts to over $95 \%$ of the value of all stocks listed in the ASX. We limit the sample stocks from the index to those that were present at the beginning and end of the sample period. We further delete stocks that were traded on fewer than 200 days over the 252 trading days in our sample. For each event day, we delete stocks that did not have both AT and nonAT trades. The final sample contains 9,896 stock trading days across 384 stocks. Table 1 reports the event days, number of stocks for each event day, and returns of the All Ords.

\section{[Insert Table 1 about here]}

Outliers are a potential concern in empirical research. Since the top 20 stocks by market capitalization account for more than $55 \%$ of the market, large movements in the market index could be caused by a few of the largest firms. Consequently, the selected days may contain days when the index change does not represent a price shift among a wide range of stocks. To eliminate this possibility, we calculate the percentages of firms with positive returns, zero returns, and negative returns. Furthermore, we calculate the ratios of stocks with positive returns

\footnotetext{
${ }^{7}$ Our data include every order in the limit order book and each order is given a unique ID. Therefore, each order's time stamp can be dynamically updated upon submission, revision, cancellation, and execution. Consequently, the trade initiator can be identified by comparing the time stamps of the ask- and bid-side orders. A trade is identified as a buy (sell) initiated when the time stamp of the ask-side (bid-side) order is older.
} 
(negative returns) to negative returns (positive returns) for positive (negative) market return days. The event days are presented in Table 1. For market up days, the mean percentage of positive return stocks is $72.40 \%$, with a maximum of $81.47 \%$ on 14 July 2009 and a minimum of $57.45 \%$ on 27 January 2009. The ratio of stocks with positive returns to stocks with negative return indicates that there are, on average, 2.75 times more stocks with positive returns than with negative returns over our sample period. The findings for market down days are qualitatively and quantitatively similar to those for market up days. Overall, the results imply that the market returns on the selected days are not driven by outliers.

Although the numbers of stocks included for each event day are not identical, the sample size for each event day is sufficiently large. The minimum is 205 on 15 January 2009 and the maximum is 340 on 14 August 2009 and 17 September 2009. The distribution of market up days is relatively spread out throughout the year. For market down days, however, there is a cluster of event days in November 2008.

\section{AT Intensity and Abnormal Returns}

We hypothesize that, in volatile markets, AT does not increase price fluctuation nor cause prices to deviate from their fundamental values by abnormally trading in the direction of broad market movement. Therefore, the cross-sectional distribution of individual stock returns will be a function of the level of AT activity. We first analyse the univariate properties of AT at the stock level and then report the multivariate regression results.

\subsection{Univariate Analysis}

To highlight cross-sectional variation in AT and nonAT activity sorted by size, we form quartiles based on the market capitalizations of the 384 stocks, with the largest-cap stocks forming the first quartile. Summary statistics for the AT and nonAT volumes (in millions of shares) between 27 October 2008 and 23 October 2009 and on event days in each of the quartiles are presented in Table 2

\section{[Insert Table 2 about here]}

Consistent with the empirical findings of Hendershott et al. (2011), AT is more prevalent in larger stocks and accounts for $75.20 \%$ of the volume traded in the largest quartile stocks. However, AT remains dominant 
throughout the four quartiles, with $59.36 \%$ of the volume traded in the smallest quartile. On event days, ATers trade slightly more than nonATers, with an average increase of $2.70 \%$. There are more increases in smaller stocks than in larger stocks, with $4.63 \%$ in the smallest quartile and $1.51 \%$ in the largest quartile. The finding supports our premise that ATers do not drastically change their trading behaviour compared to nonATers in light of extreme market movements.

Similar to Dennis and Strickland (2002), we assess the characteristics of one particular trading group, ATers, by measuring their relative trading intensity compared to the overall market. Thus, our main variable of interest is the level of AT activity in proportion to total trading activity. We measure trading activity by volume traded and the number of transactions. We then separate buy-initiated trades from sell-initiated trades to identify additional information from trade direction. Our measures are aggregated by daily frequency. We consider this frequency a good compromise between the richness of transaction data and a more comprehensive panel that represents some of the more thinly traded stocks.

Table 3 contains descriptive statistics. Panel A presents the cross-sectional averages of volume, the number of transactions, and various AT volume (number of trades) ratios measured by the ATer-initiated volume (number of trades) over the total volume (number of trades). The daily statistics are reported for all 252 trading days, including 19 up days and 20 down days identified in Table1. In line with Chordia and Subrahmanyam (2004), the number of buy trades is slightly higher than the number of sell trades, with means of 257 and 234, respectively. The average volume is 110,000 more on up days compared with all days, whereas we do not observe the same volume increase during down days. Overall, ATers initiate $68.25 \%$ of the volume and $80.84 \%$ of the trades, implying that AT trade size is much smaller than that of nonAT trades. This finding is consistent with Hendershott and Riordan (2014), in that ATers break their orders into smaller packets to achieve the best prices. Since our premise is that a higher level of AT relates negatively to price fluctuation, we use the ratio of the AT volume over the entire trading volume as our main regression analysis variable to control for trade size differences between AT and nonAT.

\section{[Insert Table 3 about here]}

Panel B of Table 3 presents the cross-sectional means of individual stock time-series correlations and autocorrelations between all AT trade, AT buy, and AT sell ratios, measured by the number of trades and volume. The 
corresponding ratios measured by the number of trades and volume are highly correlated, with correlations of 0.672, 0.666, and 0.680 for all AT trades, AT buys, and AT sells, respectively. The correlations between AT buys and AT sells measured by the number of trades and volume are 0.093 and 0.110 , respectively. Panel C contains the cross-sectional average autocorrelations of AT ratios measured by volume and the number of trades. The autocorrelation of the ratio of AT trades to all trades is substantially high; the first-lag autocorrelation is 0.211. The autocorrelations of AT buys and AT sells are smaller but also significant: 0.167 and 0.176 , respectively. The autocorrelations decay at a moderate speed. This finding suggests that ATers have a sustained preference for certain stocks. Therefore, raw AT ratios would not be suitable to disentangle the incremental differences at the AT level on volatile days. Compared to volume ratios, AT ratios measured by the number of trades have higher autocorrelations across the board. This difference could imply that market participants are splitting their orders to minimize their price impact (e.g. Chan and Fong 2000).

\subsection{Multivariate Results}

To assess how the trading activities of different investor groups correlate to individual stock returns in a volatile market, we model the market-adjusted return on each event day as a function of the AT volume ratio and control variables. The most efficient estimation method for our panel data would be a pooled ordinary least squares estimator. However, possible cross-sectional correlations in the error terms could be a problem. To mitigate this issue, we follow Dennis and Strickland (2002) and use Fama-MacBeth (1973) regression on each event day:

$$
\text { ar }_{i}=\alpha+\beta_{1} \text { abvol }_{i}+\beta_{2} \text { size }_{i}+\beta_{3} \text { turnover }_{i}+\beta_{4} \text { idiovar }_{i}+\beta_{5} \text { beta }_{i}+\epsilon_{i},
$$

where $a r_{i}$ is the market-adjusted return for stock $i$ on the event day. In Panel A of Table $4, a b v o l_{i}$ is the abnormal volume ratio between the AT volume and the overall volume on the event day less the mean volume ratio over the past five days. The decision to use abnormal volume ratios as opposed to raw volume ratios is based on the autoregressive properties reported in Table 3. Specifically, ATers are found to consistently prefer certain stocks to others. Applying the raw ratios on the event day for the cross section of stocks would incorporate the information about these preferences, whereas the purpose of our study is to analyse ATers' response to the extreme 
market movements of event days and its implications. Moreover, the decision to use five lags is determined by autocorrelation analysis, wherein the coefficients of the partial autocorrelation function quickly revert back to zero before five lags for most stocks.

In Panel B of Table 4, $a b v o l_{i}$ is further segregated into $a b b u y v o l_{i}$ and $a b s e l l v o l_{i}$, corresponding to abnormal buy volume ratios and abnormal sell volume ratios, respectively:

$$
\text { ar }_{i}=\alpha+\beta_{1} \text { abbuyvol }_{i}+\beta_{2} \text { absellvol }_{i}+\beta_{3} \text { size }_{i}+\beta_{4} \text { turnover }_{i}+\beta_{5} \text { idiovar }_{i}+\beta_{6} \text { beta }_{i}+\epsilon_{i} .
$$

We included beta as an independent variable, which is calculated based on historical returns over the past year. The magnitude of beta is directly associated with market-adjusted returns and volatility. There are two reasons to include turnover in our regression. First, previous studies have established the link between stock trades and stock price changes (for a detailed survey, see Karpoff 1987). Although our main variables capture AT/nonAT trading effects, we include turnover to account for overall liquidity effects. Second, the theoretical model of Foucault, Kadan, and Kandel (2013) predicts a strong association between AT and trading rates. Empirically, AT is reported to follow a liquidity-driven strategy (Hendershott and Riordan, 2014). If AT is correlated with liquidity in our sample, omitting turnover would be likely to force our main ratios to become proxies for liquidity effects. Therefore, we include turnover to ensure that the estimated relation between AT ratios and returns is robust to pricing and proxy effects.

As for turnover, we include size in the regression to account for its possible association with return and AT ratios 8 Moreover, the All Ords, a value-weighted index, places more weight on larger stocks. Therefore, including size could alleviate potential biases of returns towards larger stocks. We also include idiosyncratic variance in our regression. Dierkens (1991) suggests using idiosyncratic volatility as a measure of informational effects. If AT has an informational advantage, as argued by Biais et al. (2013), AT would be correlated with idiosyncratic variance.

Our main variable of interest is the intensity of AT in individual stocks in light of large market movements. We measure the association between AT ratios and market-adjusted returns for each stock. When the market suffers from a price decline of more than $2 \%$, further decline in a given stock represented by a decrease in market-adjusted return would indicate its higher volatility. If we would find more AT in stocks that have a less market-adjusted

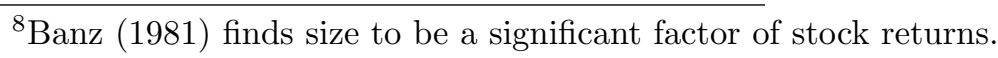


return, then AT would cause price fluctuations by exerting further downward pressure on individual stocks. Alternatively, if AT level were positively associated with market-adjusted returns on market decline days, then AT would be beneficial to stock price stability. To emphasize the importance of trade direction, we then segregate trading volume into buy and sell volumes. We expect the buy (sell) volume to be more relevant than the sell (buy) volume on market up (down) days.

Table 4 presents the estimation results. Regression estimations with unsigned AT volume ratios are reported in Panel A. The signs of the coefficients for the AT volume ratio (abvol) are as expected: negative for market up days and positive for market down days. The coefficients suggest that nonAT creates price pressure in the direction of market movement. However, the AT volume ratio (abvol) is marginally insignificant (p-value of 0.113) on market up days and insignificant (p-value of 0.181) on market down days. To further disentangle the informativeness in trade signals, we report the estimations for the AT buy volume ratio (abbuyvol) and the AT sell volume ratio (absellvol) in Panel B. On market up days, the AT buy volume ratio is significant and the AT sell volume ratio is highly insignificant, whereas the distribution of significance reverts on market down days. This result suggests that the predictive power of the buy (sell) volume on up (down) days is diluted by not assigning trade direction in Panel A. Taken together, the AT buy ratio is negatively correlated with the market-adjusted return on up days, whereas the AT sell ratio is positively correlated with the market-adjusted return on down days. This finding supports the notion that stocks with less AT buying (selling) would incur a greater upward (downward) price swing on up (down) days. As a result, stocks with higher levels of trading by ATers would reduce volatility on event days.

\section{[Insert Table 4 about here]}

Economically, the effects of AT volume ratios on market-adjusted returns are substantial. The economic significance is most pronounced when we segregate the trades into buy- and sell-initiated trades. The coefficient of the AT buy ratio on market up days is 1.61, which implies a decrease of 16 basis points in the predicted abnormal market return for a $10 \%$ increase in the abnormal AT buy ratio. The coefficient of the AT sell ratio on market down days is similar in magnitude. The coefficients of the control variables in Panels A and B of Table 4 are similar in magnitude and significance. Beta is significantly related to market-adjusted returns: Larger beta stocks have higher market-adjusted returns on market up days and lower market-adjusted returns on market down 
days. As expected, turnover is positively (negatively) related to market-adjusted returns on market up (down) days. However, the association on market down days is not significant, implying that market up days are more likely to be liquidity driven, compared to market down days. Size and idiosyncratic variance are not significantly related to market-adjusted returns.

\subsection{Robustness Tests}

We perform several tests to assess the robustness of our results. We first test an alternative construction of the abnormal AT volume ratio. Madhavan, Richardson, and Roomans (1997) argue that innovation in the order flow is more indicative for security prices if the order flow is correlated. Innovation is modelled as the 'surprise' component: the raw value less the expected value from the previous period. We follow a methodology similar to that of Brogaard et al. (2014) and model the innovation in the AT volume ratio (ivol) as the residual of a five-lag autoregressive model. Innovations in the AT buy ratio (ibuyvol) and AT sell ratio (isellvol) are obtained analogously. Table 5 presents the results using innovation in the AT volume ratios.

\section{[Insert Table 5 about here]}

The re-estimation results in Table 5 are quantitatively and qualitatively similar to the original results in Table 4. The AT volume ratio is statistically insignificant when we do not distinguish buy-initiated from sell-initiated trades and the AT buy (sell) ratio is significantly related to abnormal returns on market up (down) days, with similar coefficients. The re-estimation confirms that our finding is robust with regard to the measurement of AT volume ratios.

We also provide a sensitivity analysis of the event-day selection criteria. In Table 6, we relax the threshold of event-day selection criteria from an absolute market return of more than $2 \%$ to between $1.5 \%$ and $2.5 \%$. Furthermore, if the market moves during the day but reverses to the initial value at closing, the daily market return would not capture these days. Therefore, we replace the daily market return with the daily high (low) to open price return to capture the extreme price increase (decline) in the intraday.

\section{[Insert Table 6 about here]}


The results from alternative event-day specifications are quantitatively and qualitatively similar to those estimated from the original specifications. Finally, the result is also robust to nonconsecutive event-day selection, firm fixed effects, and double clustering of the standard error in stocks and days. For brevity, the results are not reported here but are available upon request.

\section{AT Strategies and the VWAP Metric}

To understand why AT reduces price fluctuation in volatile times, we investigate the possible strategies that ATers could employ. Easley et al. (2012) suggest that execution algorithms track the VWAP metric to reduce execution costs. The VWAP is the average price of each transaction over a certain time horizon (typically one day) weighted by the volume of each trade. The executed price of each trade can then be compared with the VWAP to evaluate the trade's execution performance. If algorithms closely monitor the intraday VWAP, then the difference between the executed price and VWAP at the time of the transaction would be small. During periods of large market swings, stock price would deviate from the VWAP. VWAP-tracking algorithms would be more patient and wait for the optimal stock price to VWAP relation. Therefore, AT would smooth out liquidity demand and would not contribute to further price swings.

\section{[Insert Figure 1 about here]}

By way of illustration, Figure 1 highlights the prices of trades initiated by ATers and nonATers and the intraday dynamics of the VWAP for Premier Investments Limited (stock symbol PMV) on 4 August 2009. In terms of trading volume, both ATers and nonATers initiate similar amounts of transactions. However, ATers initiate trades when the price is much closer to the VWAP, compared to nonATers. This finding implies that at least a substantial portion of ATers monitor the VWAP, whereas nonATers do not track the VWAP as much.

We start our analysis by testing whether ATers trade closer to the VWAP compared to nonATers. Table 7 shows the univariate results for the relation between the intraday VWAP and trades initiated by ATers and nonATers. Panel A reports the average variance from the VWAP $\left(\operatorname{var}_{i, t}\right)$, defined as the squared difference between the transacted price and the prevailing VWAP weighted by the prevailing VWAP at the time of the transaction, for both ATers and nonATers. On event and non-event days, $v r_{i, t}$ is significantly smaller for AT than for nonAT. 
Algorithms, therefore, trade significantly closer to the VWAP compared to human traders. This finding suggests that ATers employ a VWAP-tracking strategy. During turbulent markets, ATers do not alter their strategy and therefore do not exacerbate price fluctuations.

\section{[Insert Table 7 about here]}

In Panel B, variance from the VWAP is replaced with deviation from the VWAP $\left(\right.$ devi $\left._{i, t}\right)$ that measures the signed difference between the prevailing VWAP and the transaction price weighted by the VWAP. Deviation from the VWAP is interacted with an indicator variable $\left(I_{i, t}\right)$ that equals one $(-1)$ if the trade is buyer (seller) initiated. $I_{i, t} \cdot$ devi $_{i, t}$ is positive when a buy (sell) trade happens when the stock price is below (above) the prevailing VWAP. Therefore, $I_{i, t} \cdot d e v i_{i, t}$ can gauge whether and how much each trade can beat the VWAP metric. Although the average value of the measure is negative for AT and nonAT, algorithms beat human traders in regards to the intraday VWAP metric.

To more formally establish the statistical association between the intraday VWAP and the trading strategy of ATers, we estimate probit regressions for algorithm-initiated trades. Following Hendershott and Riordan (2014), we control for market conditions by including the bid-ask spread, trade size, market depth, lagged volatility, and lagged volume. We also include, but do not report, firm fixed effects and time of day dummies for each half-hour period.

\section{[Insert Table 8 about here]}

The key variable in Table 8 is $I_{i, t} \cdot i d e v i_{i, t} . I_{i, t}$ is an indicator variable that equals one (-1) if the trade is buyer (seller) initiated. Similar to Brogaard et al. (2014), idevi $i_{i, t}$ is the deviation innovation obtained as the residual of a five-lag autoregressive on the time series of $d e v i_{i, t}$. The coefficients for $I_{i, t} \cdot i d e v i_{i, t}$ is positive if ATers are more likely to trade when price-VWAP relation becomes favorable. The coefficients in Table 8 show that ATers are more likely to initiate trades when the stock price is closer to its intraday VWAP.

\section{AT and nonAT Order Imbalances}

The findings on AT volume ratios support our premise that stocks traded more by ATers exhibit less price fluctuation on event days. We provide additional explanation for the source of the cross-sectional return difference. 
One probable reason is that trades from ATers and nonATers exert different levels of price pressure. Therefore, the order imbalance from ATers and nonATers would have different price impacts. We model market-adjusted returns as a function of order imbalances from ATers and nonATers and explore our hypothesis.

Order imbalances are measured as the scaled and unscaled imbalances in the number of transactions and in volume. We separately measure each order imbalance metric for ATers and nonATers on a daily basis. The crosssectional averages of the correlations between various order imbalance metrics are reported in Panel A of Table 9 . The correlations between scaled and unscaled order imbalances are high. For example, the correlations between the unscaled and scaled volume imbalances for AT and nonAT are 0.705 and 0.730 , respectively. The correlations between volume imbalances and the number of trades imbalances are lower $(0.427$ and 0.570 , respectively for AT and nonAT). The correlations between AT and nonAT are very small across different metrics. The largest value (in absolute terms) for AT versus nonAT correlations is -0.071 . This finding highlights the heterogeneity in the trading strategies of ATers and nonATers.

\section{[Insert Table 9 about here]}

Panel B of Table 9 presents the cross-sectional averages of the autocorrelation of AT and nonAT order imbalances measured by the number of trades and volume. Domowitz and Yegerman (2005) argue that a substantial proportion of buy-side AT uses VWAP-monitoring strategies to execute trades over time to minimize execution costs. For all but one metric, nonAT daily autocorrelations in order imbalance are larger than those for AT. This result suggests that AT does not seem to break down orders across days, which minimizes any potential bias due to autocorrelation.

We model individual stock returns as a function of order imbalances by AT and nonAT. Although our order imbalance metrics have a smaller autocorrelation than those of Chordia and Subrahmanyam (2004), we include four lags of order imbalance. We also use market-adjusted returns to mitigate the cross-sectional correlation in error terms. Similar to Equation (1), we estimate the Fama-MacBeth (1973) regression for each event day:

$$
\begin{aligned}
\text { ar }_{i, t}= & \alpha+\beta_{1} \text { atoib }_{i, t}+\beta_{2} \text { nonatoib }_{i, t}+\sum_{k=1}^{4} \beta_{2+k} \text { atoib }_{i, t-k}+\sum_{k=1}^{4} \beta_{6+k} \text { nonatoib }_{i, t-k} \\
& +\beta_{11} \text { size }_{i, t}+\beta_{12} \text { turnover }_{i, t}+\beta_{13} \text { idiovar }_{i, t}+\beta_{14} \text { beta }_{i, t}+\epsilon_{i, t}
\end{aligned}
$$


where $a r_{i, t}$ is the abnormal return for stock $i$ on event day $t$, atoib $b_{i, t}$ is the volume imbalance from AT in stock $i$ on day $t$, and size $_{i, t}$, turnover $_{i, t}$, idiovar $_{i, t}$, and beta $a_{i, t}$ are defined as in Section 3.2. The control variables are included to account for risk factors, informational effects, liquidity effects, and potential preferences of ATers. The detailed rationale is discussed in Section 3.2. The regression results are presented in Panel A of Table 10 The results for lagged order imbalances are mostly insignificant and in line with the findings of Chordia and Subrahmanyam (2004). Therefore, the coefficients for lagged metrics are omitted. In Panel B, we replace the volume imbalance $\left(\right.$ atoib $_{i, t}$ and nonatoib $\left.b_{i, t}\right)$ metrics in Equation (3) with the scaled volume imbalance metrics for $\mathrm{AT}\left(\right.$ atoibscl $\left._{i, t}\right)$ and nonAT (nonatoibscl $\left.l_{i, t}\right)$. The estimation method is the same as in Equation (3).

\section{[Insert Table 10 about here]}

The core variable of interest is the order imbalance metric from ATers and from nonATers. The relation between market-adjusted returns and imbalance from the order flow can be expected from the previous literature (e.g. Chordia et al. 2002): Higher-order imbalance would create more price pressure on the buy side and cause prices to go up. In this regression, however, our objective is to find out whether order imbalances from ATers and nonATers affect abnormal return differently. In other words, if the coefficients for AT imbalances $\left(a t o i b_{i, t}\right)$ are larger than the coefficients for nonAT imbalances $\left(\right.$ nonatoib $\left._{i, t}\right)$, then the implication is that AT exerts greater price pressure compared to nonAT and the market responds differently to imbalances from the different trading groups. We expect, however, that nonAT imbalances would exert greater price pressure compared to AT, based on the results in Table 4 .

As shown in Table 10, all contemporaneous imbalance metrics are significant. The results for market up days and market down days are quantitatively and qualitatively similar. Therefore, we discuss the results on up days and down days together. For unscaled volume imbalance, the average coefficients of imbalances from AT and nonAT are 1.35 and 2.33, respectively, corresponding to a $72.59 \%$ difference in effects. The results from the scaled volume imbalance regression are more modest. The mean coefficients for AT and nonAT imbalances are 4.59 and 5.49, respectively. The impact of nonAT imbalances is $19.61 \%$ larger than that of AT imbalances. Overall, the results from the estimation are consistent with our expectation that the abnormal return and volatility of an individual stock are related to its level of AT activity. One possible reason is that ATers execute minimize the 
price pressure exerted on the traded. As a result, stocks with higher AT trading experience lower price swings on volatile days.

\section{Post-Event Day Analysis}

The empirical findings on event days indicate that the absolute value of individual stock returns with lower AT activity exceeds that of returns with higher AT activity. However, we need to find out whether the return difference is transient or permanent. In this section, we show the post-event return differences of stocks with high versus low AT activity. The return difference on the event day could be explained by nonAT reactions to information and driving prices to their fundamental value. If this is the case, we should observe no return reversal during the period immediately after the event day for stocks with lower AT activity compared to those with higher AT activity. If, however, there are significant return reversals among lower AT activity stocks, then it implies that nonAT increases volatility and causes prices to deviate from their fundamental values.

The time span of our data dictates that longer-term analysis is not feasible; nevertheless, we provide a postevent cumulative return analysis over the five days immediately after each event day. We cumulate post-event market-adjusted returns as cumulative abnormal returns (CARs) for each stock and partition them into quartiles based on their event-day AT activity. We then calculate the mean difference between higher AT activity and lower AT activity CARs. The intuition is that, if the return effects on event days are temporary, we will observe significantly higher CARs in low AT stocks compared to high AT stocks immediately after market down days. Alternatively, if the return effects are fundamental on event days, we will observe insignificant differences in post-event CARs.

\section{[Insert Table 11 about here]}

Table 11 contains the results of the post-event CAR differences. In Panel A, the first (third) row contains the mean CAR difference between the top 50\% (25\%) and bottom 50\% (25\%) based on AT activities. The second and fourth rows report the p-values corresponding to a test of a null hypothesis that the CARs from high/low AT quartiles are identical. On market down days, the post-event CAR difference is significantly negative. This finding implies significant return reversals in low AT activity stocks. 


\section{Conclusion}

We provide findings on the characteristics of AT in volatile periods. We find that the level of AT in individual stocks is statistically and economically significantly related to abnormal returns in volatile markets. In particular, stocks with lower levels of AT experience greater price swings when the absolute return of the market exceeds 2\%. In addition, the effect of AT on stock returns is likely caused by AT following VWAP-tracking strategies. We complement this finding by showing that the order imbalances from nonAT have, on average, $50 \%$ more impact on the abnormal returns of individual stocks on event days. Overall, our results support the premise that ATers execute their transactions more intelligently, which results in less price pressure and lower volatility on the stocks that they trade. Finally, we also highlight the importance of accurately differentiating trade direction in the order flow. We illustrate that identifying trade direction vastly improves the informativeness of our inferences.

However, our study is subject to a few caveats. While our sample period covers a very volatile regime, the sample size is limited to only one year. A multi-year international study could add further robustness to our findings. In addition, although we find a strong association between the level of AT and price fluctuation, it would be fruitful to further investigate the causalities between AT and stock returns. Overall, our findings have important policy implications. Since AT as a whole plays a beneficial role in volatile markets, we advise against indiscriminate restriction on ATers. Future research should focus on the heterogeneity among ATer groups and identify the nefarious algorithms, which would promote targeted policy making. 


\section{References}

Aitken, M., Frino, A., 1996. The accuracy of the tick test: evidence from the australian stock exchange. Journal of Banking and Finance 20, 1715-1729.

Australian Securities Exchange, 2010. Algorithmic trading and market access arrangements. Available at: http://www.asx.com.au/documents/media/20100211_review_algorithmic_trading_and_market_ access.pdf(retrieved on 22 February 2014).

Banz, R. W., 1981. The relationship between return and market value of common stocks. Journal of Financial Economics 9, 3-18.

Berkowitz, S. A., Logue, D. E., Noser, E. A., 1988. The total cost of transactions on the NYSE. Journal of Finance $43,97-112$.

Biais, B., Foucault, T., Moinas, S., 2013. Equilibrium fast trading. AFA 2013 San Diego Meetings Paper .

Boehmer, E., Fong, K., Wu, J., 2012a. Algorithmic trading and changes in firms equity capital. Working Paper .

Boehmer, E., Fong, K., Wu, J., 2012b. International evidence on algorithmic trading. Working Paper .

Brogaard, J., Hendershott, T., Riordan, R., 2014. High frequency trading and price discovery. Journal of Financial Economics, Forthcoming .

Carrion, A., 2013. Very fast money: high-frequency trading on the NASDAQ. Journal of Financial Markets 16, 680-711.

Chakrabarty, B., Moulton, P. C., Shkilko, A., 2012. Short sales, long sales, and the lee-ready trade classification algorithm revisited. Journal of Financial Markets 15, 467-491.

Chan, K., Fong, W.-M., 2000. Trade size, order imbalance, and the volatility-volume relation. Journal of Financial Economics 57, 247-273.

Chordia, T., Roll, R., Subrahmanyam, A., 2002. Order imbalance, liquidity, and market returns. Journal of Financial Economics 65, 111-130.

Chordia, T., Subrahmanyam, A., 2004. Order imbalance and individual stock returns: Theory and evidence. Journal of Financial Economics 72, 485-518.

Cumming, D., Zhan, F., Aitken, M., 2012. High frequency trading and end-of-day manipulation. Working Paper 12. 
Dennis, P. J., Strickland, D., 2002. Who blinks in volatile markets, individuals or institutions? Journal of Finance 57, 1923-1949.

Dierkens, N., 1991. Information asymmetry and equity issues. Journal of Financial and Quantitative Analysis 26, 181-199.

Domowitz, I., Yegerman, H., 2005. The cost of algorithmic trading: a first look at comparative performance. Trading 2005, 30-40.

Easley, D., Lopez de Prado, M., O’Hara, M., 2012. The volume clock: Insights into the high frequency paradigm. Journal of Portfolio Management, Forthcoming .

Ellis, K., Michaely, R., O'Hara, M., 2000. The accuracy of trade classification rules: evidence from NASDAQ. Journal of Financial and Quantitative Analysis 35, 529-551.

Fama, E. F., MacBeth, J. D., 1973. Risk, return, and equilibrium: empirical tests. Journal of Political Economy pp. 607-636.

Foucault, T., Kadan, O., Kandel, E., 2013. Liquidity cycles and make/take fees in electronic markets. Journal of Finance 68, 299-341.

Frino, A., Viljoen, T., Wang, G. H., Westerholm, J., Zheng, H., 2014. Are algorithmic trades informed? An empirical analysis of algorithmic trading around earnings announcements. Working Paper .

Hasbrouck, J., Saar, G., 2013. Low-latency trading. Journal of Financial Markets 16, 646-679.

Hasbrouck, J., Seppi, D. J., 2001. Common factors in prices, order flows, and liquidity. Journal of Financial Economics 59, 383-411.

Hendershott, T., Jones, C. M., Menkveld, A. J., 2011. Does algorithmic trading improve liquidity? Journal of Finance 66, 1-33.

Hendershott, T., Riordan, R., 2014. Algorithmic trading and the market for liquidity. Journal of Financial and Quantitative Analysis, Forthcoming .

Karpoff, J. M., 1987. The relation between price changes and trading volume: a survey. Journal of Financial and Quantitative Analysis 22, 109-126.

Kirilenko, A., Kyle, A. S., Samadi, M., Tuzun, T., 2011. The flash crash: The impact of high frequency trading on an electronic market. Working Paper .

Lee, C., Ready, M. J., 1991. Inferring trade direction from intraday data. Journal of Finance 46, 733-746. 
Madhavan, A., Richardson, M., Roomans, M., 1997. Why do security prices change? A transaction-level analysis of NYSE stocks. Review of Financial Studies 10, 1035-1064.

Madhavan, A. N., 2002. Vwap strategies. Trading 2002, 32-39.

Martinez, V. H., Rosu, I., 2013. High frequency traders, news and volatility. AFA 2013 San Diego Meetings Paper

U.S. Securities and Exchange Commission, 2010. Concept release on equity market structure. Available at: http: //www.sec.gov/rules/concept/2010/34-61358.pdf (retrieved on 22 February 2014).

Zhang, F., 2010. High-frequency trading, stock volatility, and price discovery. Working Paper . 
Table 1: Event Days and Returns

This table contains the dates, market returns, and number of stocks in the sample and the proportion of stocks that have positive, zero, and negative returns on days when the absolute value of the return of the market portfolio exceeds $2 \%$. The sample period is from 27 October 2008 to 23 October 2009. Stocks are included on each event day if they were traded by both ATers and nonATers on the day. The market portfolio is defined as the Australian All Ords. In this table, percent positive is the percentage of stocks with returns greater than zero, percent zero is the percentage of stocks with returns equal to zero, percent negative is the percentage of stocks with returns less than zero, and ratio is the ratio of percent positive (negative) to percent negative (positive) on market up (down) days. There are 19 up days and 20 down days in our sample.

\begin{tabular}{|c|c|c|c|c|c|c|}
\hline Date & $\begin{array}{c}\text { Market } \\
\text { Return } \\
(\%)\end{array}$ & $\begin{array}{l}\text { Number } \\
\text { of Stocks }\end{array}$ & $\begin{array}{l}\text { Percent } \\
\text { Positive }\end{array}$ & $\begin{array}{c}\text { Percent } \\
\text { Zero }\end{array}$ & $\begin{array}{l}\text { Percent } \\
\text { Negative }\end{array}$ & Ratio \\
\hline \multicolumn{7}{|c|}{ Panel A: Market Up Days } \\
\hline 05-Nov-08 & 2.82 & 277 & 72.92 & 5.78 & 21.30 & 3.42 \\
\hline 25-Nov-08 & 5.51 & 253 & 73.52 & 7.91 & 18.58 & 3.96 \\
\hline $28-\mathrm{Nov}-08$ & 4.10 & 244 & 73.77 & 8.61 & 17.62 & 4.19 \\
\hline 08-Dec-08 & 3.69 & 221 & 71.04 & 4.98 & 23.98 & 2.96 \\
\hline 15-Dec-08 & 2.41 & 224 & 72.32 & 4.46 & 23.21 & 3.12 \\
\hline 27-Jan-09 & 2.79 & 235 & 57.45 & 8.94 & 33.62 & 1.71 \\
\hline 13-Mar-09 & 3.27 & 242 & 80.99 & 4.96 & 14.05 & 5.76 \\
\hline 17-Mar-09 & 2.91 & 252 & 75.00 & 5.16 & 19.84 & 3.78 \\
\hline 23-Mar-09 & 2.29 & 241 & 64.73 & 8.30 & 26.97 & 2.40 \\
\hline 02-Apr-09 & 2.69 & 269 & 76.58 & 5.58 & 17.84 & 4.29 \\
\hline 14-Apr-09 & 2.22 & 274 & 75.55 & 5.84 & 18.61 & 4.06 \\
\hline 30-Apr-09 & 2.26 & 265 & 76.98 & 5.28 & 17.74 & 4.34 \\
\hline 04-May-09 & 2.89 & 266 & 73.31 & 5.64 & 21.05 & 3.48 \\
\hline 19-May-09 & 2.12 & 274 & 67.52 & 6.93 & 25.55 & 2.64 \\
\hline 10-Jun-09 & 2.10 & 277 & 67.51 & 10.11 & 22.38 & 3.02 \\
\hline 14-Jul-09 & 3.23 & 259 & 81.47 & 8.11 & 10.42 & 7.81 \\
\hline 13-Aug-09 & 2.74 & 340 & 73.75 & 5.01 & 21.24 & 3.47 \\
\hline 16-Sep-09 & 2.32 & 334 & 71.56 & 8.68 & 19.76 & 3.62 \\
\hline 07-Oct-09 & 2.15 & 330 & 69.70 & 8.48 & 21.82 & 3.19 \\
\hline
\end{tabular}


Table 1 Continued

\begin{tabular}{|c|c|c|c|c|c|c|}
\hline Date & $\begin{array}{c}\text { Market } \\
\text { Return } \\
(\%)\end{array}$ & $\begin{array}{l}\text { Number } \\
\text { of Stocks }\end{array}$ & $\begin{array}{l}\text { Percent } \\
\text { Positive }\end{array}$ & $\begin{array}{c}\text { Percent } \\
\text { Zero }\end{array}$ & $\begin{array}{l}\text { Percent } \\
\text { Negative }\end{array}$ & Ratio \\
\hline \multicolumn{7}{|c|}{ Panel B: Market Down Days } \\
\hline 06-Nov-08 & -4.22 & 233 & 13.30 & 3.00 & 83.69 & 6.29 \\
\hline 07-Nov-08 & -2.43 & 236 & 34.75 & 5.51 & 59.75 & 1.72 \\
\hline 11-Nov-08 & -3.40 & 224 & 15.18 & 2.68 & 82.14 & 5.41 \\
\hline 13-Nov-08 & -5.44 & 220 & 8.64 & 5.00 & 86.36 & 10.00 \\
\hline 17-Nov-08 & -2.32 & 225 & 22.67 & 6.22 & 71.11 & 3.14 \\
\hline 18-Nov-08 & -3.47 & 238 & 15.13 & 5.88 & 78.99 & 5.22 \\
\hline 20-Nov-08 & -4.32 & 266 & 14.29 & 5.64 & 80.08 & 5.61 \\
\hline 26-Nov-08 & -2.68 & 225 & 23.56 & 8.44 & 68.00 & 2.89 \\
\hline 02-Dec-08 & -4.02 & 217 & 13.82 & 5.53 & 80.65 & 5.83 \\
\hline 12-Dec-08 & -2.31 & 211 & 29.38 & 5.21 & 65.40 & 2.23 \\
\hline 08-Jan-09 & -2.27 & 220 & 20.91 & 4.55 & 74.55 & 3.57 \\
\hline 15-Jan-09 & -4.07 & 205 & 2.93 & 4.39 & 92.68 & 31.67 \\
\hline 20-Jan-09 & -3.00 & 223 & 15.25 & 4.04 & 80.72 & 5.29 \\
\hline 23-Jan-09 & -3.83 & 216 & 13.43 & 6.48 & 80.09 & 5.97 \\
\hline 02-Mar-09 & -2.82 & 225 & 22.22 & 7.11 & 70.67 & 3.18 \\
\hline 08-Apr-09 & -2.22 & 255 & 20.78 & 4.71 & 74.51 & 3.58 \\
\hline 21-Apr-09 & -2.40 & 265 & 19.25 & 2.64 & 78.11 & 4.06 \\
\hline 14-May-09 & -3.43 & 277 & 13.72 & 2.17 & 84.12 & 6.13 \\
\hline 23-Jun-09 & -3.01 & 308 & 11.04 & 6.17 & 82.79 & 7.50 \\
\hline 02-Oct-09 & -2.04 & 331 & 9.37 & 4.23 & 86.40 & 9.23 \\
\hline
\end{tabular}


Table 2: AT versus nonAT Trading Volumes (in Millions of Shares) by Stock Size

This table contains the volume statistics for AT and nonAT from 27 October 2008 to 23 October 2009 and on event days. The sample comprises 384 stocks based on the filtering criteria in Section 2. The event days are defined as the days when the absolute values of market returns exceeded $2 \%$. The AT and nonAT volumes are partitioned into four quartiles based on stock size. Size is defined as the closing market price multiplied by the number of shares outstanding on 23 October 2009. Volume is presented in millions of shares. The volume fraction for each investor group is calculated and presented in parentheses.

\begin{tabular}{|c|c|c|c|c|c|}
\hline & q1(large) & $\mathrm{q}^{2}$ & q3 & q4(small) & Total \\
\hline \multicolumn{6}{|c|}{ Panel A: AT/NonAT Volume on All Days } \\
\hline \multirow[t]{2}{*}{$\overline{\mathrm{AT}}$} & 59,143 & 26,083 & 15,036 & 6,459 & 106,721 \\
\hline & $(75.20 \%)$ & $(71.03 \%)$ & $(58.75 \%)$ & $(59.36 \%)$ & $(70.29 \%)$ \\
\hline \multirow[t]{2}{*}{ NonAT } & 19,501 & 10,636 & 10,557 & 4,423 & 45,117 \\
\hline & $(24.80 \%)$ & $(28.97 \%)$ & $(41.25 \%)$ & $(40.64 \%)$ & $(29.71 \%)$ \\
\hline \multirow[t]{2}{*}{ All } & 78,644 & 36,720 & 25,593 & 10,882 & 151,838 \\
\hline & $(100.00 \%)$ & $(100.00 \%)$ & $(100.00 \%)$ & $(100.00 \%)$ & $(100.00 \%)$ \\
\hline \multicolumn{6}{|c|}{ Panel B: AT/NonAT Volume on Event Days } \\
\hline \multirow[t]{2}{*}{$\overline{\mathrm{AT}}$} & 9,407 & 3,917 & 2,274 & 1,081 & 16,679 \\
\hline & $(76.71 \%)$ & $(73.23 \%)$ & $(64.02 \%)$ & $(63.99 \%)$ & $(72.99 \%)$ \\
\hline \multirow[t]{2}{*}{ NonAT } & 2,855 & 1,432 & 1,278 & 608 & 6,173 \\
\hline & $(23.29 \%)$ & $(26.77 \%)$ & $(35.98 \%)$ & $(36.01 \%)$ & $(27.01 \%)$ \\
\hline \multirow[t]{2}{*}{ All } & 12,262 & 5,349 & 3,552 & 1,689 & 22,852 \\
\hline & $(100.00 \%)$ & $(100.00 \%)$ & $(100.00 \%)$ & $(100.00 \%)$ & $(100.00 \%)$ \\
\hline
\end{tabular}


Table 3: $\quad$ Descriptive Statistics for AT Volume Ratios

This table contains summary statistics for daily AT ratios between 27 October 2008 and 23 October 2009. The sample comprises 384 stocks based on the filtering criteria in Section 2. The event days are defined as the days when the absolute values of the market returns exceed $2 \%$. The AT volume ratio is defined as the ratio between the AT volume and the overall volume daily. Other ratios are defined analogously. Panel A presents the means and standard deviations of the overall ratios and on event days. Panels $\mathrm{B}$ and $\mathrm{C}$ present the cross-sectional means of the individual stock time series correlations and autocorrelations. There are 252 trading days, 19 up days, and 20 down days.

\section{Panel A: Descriptive Statistics}

\begin{tabular}{|c|c|c|c|c|c|c|}
\hline & \multicolumn{2}{|c|}{ All Days } & \multicolumn{2}{|c|}{ Up Days } & \multicolumn{2}{|c|}{ Down Days } \\
\hline & Mean & Std. Dev. & Mean & Std. Dev. & Mean & Std. Dev. \\
\hline$\overline{\text { Buy Volume }(, 000)}$ & 794 & 738 & 904 & 704 & 574 & 424 \\
\hline Sell Volume $(, 000)$ & 775 & 647 & 720 & 548 & 695 & 483 \\
\hline No. of Buy Trades & 257 & 130 & 295 & 135 & 250 & 123 \\
\hline No. of Sell Trades & 234 & 114 & 220 & 103 & 238 & 104 \\
\hline AT Volume Ratio (\%) & 68.25 & 17.26 & 69.97 & 16.76 & 71.56 & 15.89 \\
\hline AT Buy Volume Ratio (\%) & 68.22 & 18.27 & 69.74 & 17.46 & 69.64 & 16.38 \\
\hline AT Sell Volume Ratio (\%) & 67.24 & 19.01 & 67.21 & 18.91 & 69.86 & 17.25 \\
\hline AT No. of Trades Ratio (\%) & 80.84 & 11.75 & 81.40 & 11.33 & 81.75 & 10.47 \\
\hline AT No. of Buy Trades Ratio (\%) & 79.56 & 12.46 & 80.67 & 11.53 & 80.08 & 10.85 \\
\hline AT No. of Sell Trades Ratio (\%) & 79.32 & 12.84 & 79.06 & 12.68 & 80.43 & 11.62 \\
\hline
\end{tabular}

\section{Panel B: Correlations}

\begin{tabular}{lccccc}
\hline & AT Buy & AT Sell & AT No. of & AT No. of & AT No. of \\
& Volume & Volume & Trades & Buy Trades & Rell Trades \\
& Ratio & Ratio & Ratio & 0.440 & 0.484 \\
\hline AT Volume Ratio & 0.622 & 0.678 & 0.672 & 0.666 & 0.090 \\
AT Buy Volume Ratio & & 0.093 & 0.435 & 0.090 & 0.680 \\
AT Sell Volume Ratio & & & 0.441 & 0.649 & 0.643 \\
AT No. of Trades Ratio & & & & \\
AT No. of Buy Trades Ratio & & & & & \\
\hline
\end{tabular}

\section{Panel C: Autocorrelations}

\begin{tabular}{cccccccc}
\hline & \multicolumn{3}{c}{ AT Volume Ratios } & & \multicolumn{3}{c}{ AT No. of Trades Ratios } \\
\cline { 2 - 4 } \cline { 6 - 7 } lag & All Trades & Buy Trades & Sell Trades & & All Trades & Buy Trades & Sell Trades \\
\hline 1 & 0.211 & 0.167 & 0.176 & 0.254 & 0.211 & 0.204 \\
2 & 0.149 & 0.118 & 0.109 & 0.191 & 0.150 & 0.142 \\
3 & 0.116 & 0.085 & 0.082 & & 0.159 & 0.117 & 0.113 \\
4 & 0.100 & 0.075 & 0.071 & & 0.140 & 0.102 & 0.093 \\
5 & 0.087 & 0.059 & 0.056 & 0.127 & 0.086 & 0.085 \\
\hline
\end{tabular}


Table 4: Event-Day Market-Adjusted Return Regressions on Abnormal AT Ratios This table presents coefficient estimates from Fama-MacBeth regressions using the following model:

$$
a r_{i}=\alpha+\beta_{1} a_{b v o l}+\beta_{2} \text { size }_{i}+\beta_{3} \text { turnover }_{i}+\beta_{4} \text { idiovar }_{i}+\beta_{5} \text { beta }_{i}+\epsilon_{i},
$$

where $a r_{i}$ is the market-adjusted abnormal return for stock $i$ on the event day. The event days are defined as the days when the absolute values of market returns exceed $2 \%$. In Panel A, abvol $i$ is the abnormal volume ratio between the AT volume and the overall volume on the event day less the mean volume ratio over the past five days. The term $s_{i z e_{i}}$ is the logarithm of the market value of stock $i$ five days prior to the event day and turnover $_{i}$ is the ratio of the daily volume over the number of shares outstanding on the event day. The variable idiovar $_{i}$ is the idiosyncratic variance of the market model residual of stock $i$ on days $[-125,-5]$ and beta $a_{i}$ is the beta of stock $i$ for days $[-125,-5]$. The p-values are reported from a t-test of the mean being different from zero. The event days are segregated into 19 up days and 20 down days. In Panel $\mathrm{B}$, abvol $_{i}$ is further segregated into abbuyvol $i$ and absellvol $_{i}$ corresponding to the abnormal buy volume ratio and the abnormal sell volume ratio, respectively:

$$
\text { ar }_{i}=\alpha+\beta_{1} \text { abbuyvol }_{i}+\beta_{2} \text { absellvol }_{i}+\beta_{3} \text { size }_{i}+\beta_{4} \text { turnover }_{i}+\beta_{5} \text { idiovar }_{i}+\beta_{6} \text { beta }_{i}+\epsilon_{i} .
$$

The control variables are identical to those in Panel A. The coefficients for abvol $_{i}$, abbuyvol $_{i}$, absellvol $_{i}$, and beta $a_{i}$ are

\begin{tabular}{|c|c|c|c|c|c|c|c|c|}
\hline & \multicolumn{4}{|c|}{ Up Days } & \multicolumn{4}{|c|}{ Down Days } \\
\hline & Mean & p-Value & Min & Max & Mean & p-Value & Min & Max \\
\hline \multicolumn{9}{|c|}{ Panel A: Aggregated AT Ratio } \\
\hline abvol & -1.01 & 0.113 & -5.22 & 3.98 & 0.73 & 0.181 & -2.83 & 6.47 \\
\hline beta & 1.86 & 0.000 & -0.12 & 4.74 & -1.93 & 0.000 & -4.66 & 0.29 \\
\hline turnover & 0.60 & 0.001 & -0.72 & 1.94 & -0.36 & 0.239 & -3.54 & 2.57 \\
\hline size & -0.19 & 0.838 & -5.10 & 10.49 & 0.09 & 0.889 & -4.42 & 8.40 \\
\hline idiovar & 0.42 & 0.380 & -3.61 & 4.53 & -0.58 & 0.316 & -3.71 & 5.22 \\
\hline \multicolumn{9}{|c|}{ Panel B: Segregated Buy/Sell Ratio } \\
\hline abbuyvol & -1.61 & 0.005 & -6.54 & 1.43 & -0.31 & 0.579 & -3.61 & 6.18 \\
\hline absellvol & -0.13 & 0.764 & -3.52 & 2.80 & 1.19 & 0.011 & -2.58 & 5.05 \\
\hline beta & 1.86 & 0.000 & -0.11 & 4.80 & -1.95 & 0.000 & -4.58 & 0.52 \\
\hline turnover & 0.59 & 0.002 & -0.91 & 1.98 & -0.33 & 0.272 & -3.68 & 2.66 \\
\hline size & -0.24 & 0.803 & -5.35 & 10.46 & 0.13 & 0.848 & -4.13 & 8.41 \\
\hline idiovar & 0.39 & 0.427 & -3.69 & 4.57 & -0.61 & 0.300 & -3.63 & 5.20 \\
\hline
\end{tabular}
multiplied by 100 in both panels. The coefficients for size $i$ are multiplied by 1,000. 
Table 5: Event-Day Market-Adjusted Return Regressions on Abnormal AT Ratios (Robustness Test) This table presents coefficient estimates from Fama-MacBeth regressions using the following model:

$$
\operatorname{ar}_{i}=\alpha+\beta_{1} \text { ivol }_{i}+\beta_{2} \text { size }_{i}+\beta_{3} \text { turnover }_{i}+\beta_{4} \text { idiovar }_{i}+\beta_{5} \text { beta }_{i}+\epsilon_{i},
$$

where $a r_{i}$ is the market-adjusted abnormal return for stock $i$ on the event day. The event days are defined as the days when the absolute values of market returns exceed $2 \%$. In Panel A, ivol $l_{i}$ is volume ratio innovation obtained as the residual of an autoregressive model with five lags applied to the individual stock volume ratios. The term size $e_{i}$ is the logarithm of the market value of stock $i$ five days prior to the event day and turnover $_{i}$ is the ratio of the daily volume over the number of shares outstanding on the event day. The variable idiovar $_{i}$ is the idiosyncratic variance of the market model residual of stock $i$ on days $[-125,-5]$ and beta $a_{i}$ is the beta of stock $i$ for days $[-125,-5]$. The p-values are reported from a t-test of the mean being different from zero. The event days are segregated into 19 up days and 20 down days. In Panel $\mathrm{B}$, ivol $_{i}$ is further segregated into ibuyvol $_{i}$ and $i_{\text {sellvol }}$, corresponding to the abnormal buy volume ratio and the abnormal sell volume ratio, respectively:

$$
\text { ar }_{i}=\alpha+\beta_{1} \text { ibuyvol }_{i}+\beta_{2} \text { isellvol }_{i}+\beta_{3} \text { size }_{i}+\beta_{4} \text { turnover }_{i}+\beta_{5} \text { idiovar }_{i}+\beta_{6} \text { beta }_{i}+\epsilon_{i} .
$$

The control variables are identical to those in Panel A. The coefficients for $i_{v o l}$, ibuyvol $_{i}$, isellvol $_{i}$, and beta $_{i}$ are multiplied

\begin{tabular}{|c|c|c|c|c|c|c|c|c|}
\hline & \multicolumn{4}{|c|}{ Up Days } & \multicolumn{4}{|c|}{ Down Days } \\
\hline & Mean & p-Value & Min & Max & Mean & p-Value & Min & $\operatorname{Max}$ \\
\hline \multicolumn{9}{|c|}{ Panel A: Aggregated AT Ratio } \\
\hline ivol & -0.93 & 0.160 & -5.43 & 4.30 & 0.48 & 0.378 & -3.22 & 5.58 \\
\hline beta & 1.86 & 0.000 & -0.15 & 4.75 & -1.94 & 0.000 & -4.66 & 0.32 \\
\hline turnover & 0.60 & 0.001 & -0.71 & 1.94 & -0.36 & 0.235 & -3.54 & 2.56 \\
\hline size & -0.15 & 0.871 & -4.87 & 10.42 & 0.09 & 0.891 & -4.52 & 8.42 \\
\hline idiovar & 0.42 & 0.391 & -3.74 & 4.54 & -0.56 & 0.338 & -3.65 & 5.28 \\
\hline \multicolumn{9}{|c|}{ Panel B: Segregated Buy/Sell Ratio } \\
\hline ibuyvol & -1.65 & 0.005 & -6.48 & 1.58 & -0.49 & 0.398 & -4.06 & 5.52 \\
\hline isellvol & 0.10 & 0.820 & -2.98 & 3.57 & 0.94 & 0.059 & -3.44 & 5.17 \\
\hline beta & 1.87 & 0.000 & -0.12 & 4.80 & -1.95 & 0.000 & -4.64 & 0.59 \\
\hline turnover & 0.59 & 0.002 & -0.85 & 2.02 & -0.35 & 0.255 & -3.71 & 2.62 \\
\hline size & -0.11 & 0.902 & -4.91 & 10.49 & 0.11 & 0.871 & -4.34 & 8.38 \\
\hline idiovar & 0.36 & 0.462 & -3.90 & 4.52 & -0.58 & 0.319 & -3.50 & 5.29 \\
\hline
\end{tabular}
by 100 in both panels. The coefficients for $s^{2} e_{i}$ are multiplied by 1,000 . 
Table 6: $\quad$ Sensitivity Test for Event-Day Selection

This table presents coefficient estimates from Fama-MacBeth regressions using the following model:

$$
\text { ar }_{i}=\alpha+\beta_{1} \text { abbuyvol }_{i}+\beta_{2} \text { absellvol }_{i}+\beta_{3} \text { size }_{i}+\beta_{4} \text { turnover }_{i}+\beta_{5} \text { idiovar }_{i}+\beta_{6} \text { beta }_{i}+\epsilon_{i} .
$$

Sensitivity analysis of the event-day selection method is presented based on the absolute value of market returns exceeding the range from $1.5 \%$ to $2.5 \%$. In the last column, we estimate the event days when the absolute value of the end-of-day high/low return exceeds $2 \%$. The variable $a r_{i}$ is the market-adjusted abnormal return for stock $i$ on the event day; abbuyvol $_{i}\left(\right.$ absellvol $\left._{i}\right)$ is the abnormal volume ratio between the AT buy (sell) volume and the overall buy (sell) volume on the event day less the mean volume ratio over the past five days; size $e_{i}$ is the logarithm of the market value of stock $i$ five days prior to the event day; turnover $_{i}$ is the ratio of the daily volume to the number of shares outstanding on the event day; idiovar $_{i}$ is the idiosyncratic variance of the market model residual of stock $i$ on days [-125, -5]; and beta $a_{i}$ is the beta of stock $i$ for days $[-125,-5]$. The p-values are reported in parentheses. the coefficients for abbuyvol ${ }_{i}$ absellvol $_{i}$, and $b^{2} t a_{i}$ are multiplied by 100 in both panels. The coefficients for size $e_{i}$ are multiplied by 1,000.

\begin{tabular}{|c|c|c|c|c|c|c|}
\hline & $1.50 \%$ & $1.75 \%$ & $2 \%$ & $2.25 \%$ & $2.50 \%$ & high/low \\
\hline No. of Up Days & 32 & 25 & 19 & 14 & 10 & 23 \\
\hline No. of Down Days & 29 & 24 & 20 & 18 & 13 & 31 \\
\hline \multicolumn{7}{|c|}{ Panel A: Market Up Days } \\
\hline abbuy & $\begin{array}{c}-1.199 \\
(0.012)\end{array}$ & $\begin{array}{l}-1.528 \\
(0.008)\end{array}$ & $\begin{array}{c}-1.606 \\
(0.005)\end{array}$ & $\begin{array}{c}-1.834 \\
(0.016)\end{array}$ & $\begin{array}{l}-1.592 \\
(0.101)\end{array}$ & $\begin{array}{l}-1.510 \\
(0.002)\end{array}$ \\
\hline absell & $\begin{array}{c}-0.202 \\
(0.494)\end{array}$ & $\begin{array}{c}-0.104 \\
(0.772)\end{array}$ & $\begin{array}{l}-0.128 \\
(0.764)\end{array}$ & $\begin{array}{c}-0.137 \\
(0.775)\end{array}$ & $\begin{array}{c}0.064 \\
(0.923)\end{array}$ & $\begin{array}{c}0.041 \\
(0.920)\end{array}$ \\
\hline beta & $\begin{array}{c}1.527 \\
(0.000)\end{array}$ & $\begin{array}{c}1.664 \\
(0.000)\end{array}$ & $\begin{array}{c}1.865 \\
(0.000)\end{array}$ & $\begin{array}{c}1.901 \\
(0.000)\end{array}$ & $\begin{array}{c}1.705 \\
(0.003)\end{array}$ & $\begin{array}{c}1.632 \\
(0.000)\end{array}$ \\
\hline turnover & $\begin{array}{c}0.475 \\
(0.000)\end{array}$ & $\begin{array}{c}0.539 \\
(0.001)\end{array}$ & $\begin{array}{c}0.587 \\
(0.002)\end{array}$ & $\begin{array}{c}0.642 \\
(0.008)\end{array}$ & $\begin{array}{c}0.611 \\
(0.042)\end{array}$ & $\begin{array}{c}0.461 \\
(0.007)\end{array}$ \\
\hline size & $\begin{array}{c}-0.800 \\
(0.313)\end{array}$ & $\begin{array}{l}-1.320 \\
(0.142)\end{array}$ & $\begin{array}{l}-0.236 \\
(0.803)\end{array}$ & $\begin{array}{c}0.105 \\
(0.929)\end{array}$ & $\begin{array}{c}0.746 \\
(0.646)\end{array}$ & $\begin{array}{c}0.328 \\
(0.721)\end{array}$ \\
\hline idiovar & $\begin{array}{c}0.163 \\
(0.663)\end{array}$ & $\begin{array}{c}0.194 \\
(0.645)\end{array}$ & $\begin{array}{c}0.387 \\
(0.427)\end{array}$ & $\begin{array}{c}0.334 \\
(0.601)\end{array}$ & $\begin{array}{c}0.565 \\
(0.406) \\
\end{array}$ & $\begin{array}{c}0.645 \\
(0.897)\end{array}$ \\
\hline \multicolumn{7}{|c|}{ Panel B: Market Down Days } \\
\hline abbuy & $\begin{array}{c}-0.485 \\
(0.246)\end{array}$ & $\begin{array}{l}-0.475 \\
(0.345)\end{array}$ & $\begin{array}{c}-0.313 \\
(0.579)\end{array}$ & $\begin{array}{l}-0.416 \\
(0.532)\end{array}$ & $\begin{array}{c}-0.854 \\
(0.246)\end{array}$ & $\begin{array}{l}-0.301 \\
(0.495)\end{array}$ \\
\hline absell & $\begin{array}{c}0.829 \\
(0.021)\end{array}$ & $\begin{array}{c}0.790 \\
(0.057)\end{array}$ & $\begin{array}{c}1.194 \\
(0.011)\end{array}$ & $\begin{array}{c}1.117 \\
(0.027)\end{array}$ & $\begin{array}{c}1.260 \\
(0.036)\end{array}$ & $\begin{array}{c}0.827 \\
(0.021)\end{array}$ \\
\hline beta & $\begin{array}{c}-1.719 \\
(0.000)\end{array}$ & $\begin{array}{l}-1.796 \\
(0.000)\end{array}$ & $\begin{array}{l}-1.953 \\
(0.000)\end{array}$ & $\begin{array}{c}-2.004 \\
(0.000)\end{array}$ & $\begin{array}{l}-2.126 \\
(0.000)\end{array}$ & $\begin{array}{c}1.447 \\
(0.000)\end{array}$ \\
\hline turnover & $\begin{array}{c}-0.315 \\
(0.239)\end{array}$ & $\begin{array}{l}-0.426 \\
(0.175)\end{array}$ & $\begin{array}{c}0.330 \\
(0.272)\end{array}$ & $\begin{array}{c}-0.368 \\
(0.277)\end{array}$ & $\begin{array}{c}-0.394 \\
(0.396)\end{array}$ & $\begin{array}{l}-0.434 \\
(0.124)\end{array}$ \\
\hline size & $\begin{array}{c}-0.884 \\
(0.218)\end{array}$ & $\begin{array}{c}0.047 \\
(0.937)\end{array}$ & $\begin{array}{c}0.130 \\
(0.848)\end{array}$ & $\begin{array}{c}-0.012 \\
(0.988)\end{array}$ & $\begin{array}{c}0.375 \\
(0.701)\end{array}$ & $\begin{array}{c}0.398 \\
(0.532)\end{array}$ \\
\hline idiovar & $\begin{array}{c}-0.663 \\
(0.155)\end{array}$ & $\begin{array}{c}-0.531 \\
(0.298)\end{array}$ & $\begin{array}{l}-0.610 \\
(0.300)\end{array}$ & $\begin{array}{c}-0.526 \\
(0.411)\end{array}$ & $\begin{array}{l}-1.205 \\
(0.084)\end{array}$ & $\begin{array}{c}0.417 \\
(0.451)\end{array}$ \\
\hline
\end{tabular}


Table 7: AT versus NonAT Variance from the VWAP

This table presents the variance from the VWAP from AT and nonAT. The VWAP for stock $i$ at time $t$ is defined as

$$
V W A P_{i, t}=\frac{\sum_{j=0}^{t} \operatorname{Vol}_{i, j} \text { Price }_{i, j}}{\sum_{j=0}^{t} \operatorname{Vol}_{i, j}},
$$

where $V o l_{i, j}$ and Price $_{i, j}$ are the volume and price of the trade at time $j$ for stock $i$, respectively, and $V W A P_{i, t}$ resets every trading day. We then calculate the variance of each trade relative to the prevailing VWAP at the time (without incorporating the trade at the time):

$$
\operatorname{var}_{i, t}=\left(\frac{\text { Price }_{i, t}-V W A P_{i, t-1}}{V W A P_{i, t-1}}\right)^{2} .
$$

Panel A contains the variance from the VWAP $\left(v a r_{i, t}\right)$ per trade for AT and nonAT on all days, non-event days, and event days. In Panel B, variance from the VWAP is replaced by deviation from the VWAP (devi $\left.i_{i, t}\right)$ with a buy/sell indicator $\left(I_{i, t}\right)$ that is one (or -1$)$ if the trade is initiated by a buyer (or seller):

$$
\text { devi } i_{i, t}=\frac{V W A P_{i, t-1}-\text { Price }_{i, t}}{V W A P_{i, t-1}} .
$$

The p-values in parentheses correspond to a test of a null hypothesis that the variances of AT and nonAT trades have identical means. All coefficients are multiplied by 1,000 .

\begin{tabular}{lcccc}
\hline & All & Nays & Non-Event & Up \\
Days & Days & Down \\
Panel A: Variance from the VWAP $\left(\right.$ var $\left._{i, t}\right)$ & & & \\
\hline AT & 0.167 & 0.158 & 0.200 & 0.235 \\
NonAT & 0.337 & 0.332 & 0.338 & 0.390 \\
AT less nonAT & -0.170 & -0.174 & -0.138 & -0.154 \\
\multicolumn{1}{l}{ Panel B: Deviation from VWAP with Buy/Sell Indicator $\left(I_{i, t}\right.$ devi $\left.i_{i, t}\right)$} & $(0.005)$ & $(0.026)$ \\
\hline AT & $(0.005)$ & -0.140 & -0.180 & -0.161 \\
NonAT & -0.145 & -0.177 & -0.193 & -0.174 \\
AT less nonAT & -0.178 & 0.037 & 0.013 & 0.013 \\
& 0.033 & $(0.000)$ & $(0.559)$ & $(0.461)$ \\
\hline
\end{tabular}


Table 8: Probit Regression for AT and the VWAP

This table presents the coefficient estimates from probit regression using the following model:

$$
a t_{i, t}=\alpha+\beta_{1} I_{i, t} \cdot \text { idevi }_{i, t}+\beta_{2} \text { spread }_{i, t}+\beta_{3} \text { size }_{i, t}+\beta_{4} \text { depth }_{i, t}+\beta_{5} \text { vola }_{i, t}+\beta_{5} \text { vol }_{i, t}+\epsilon_{i, t},
$$

where $a t_{i, t}$ equals one if the trade of stock $i$ at time $t$ is AT initiated and zero otherwise; idevi $i_{i, t}$ is the innovation of deviation from the VWAP (devi $i_{i, t}$, defined in Table 7), measured as the residual of an $\operatorname{AR}(5)$ autoregression; $I_{i, t}$ is an indicator variable which is equal to one (-1) for a buy (sell) trade; spread $_{i, t}$ is the quoted bid-ask spread; size $e_{i, t}$ is the dollar volume of the trade; depth $h_{i, t}$ is the market depth at the best bid and ask; and vola $_{i, t}$ and $v l_{i, t}$ are the lagged volatility and lagged volume, respectively, in the 15 minutes before the trade. Lagged volatility is measured as the absolute value of the stock return over the interval and lagged volume is the total volume over the interval. Stock fixed effects and time of day dummies for each half-hour of the trading day are included but not reported. In the second column, $I_{i, t} \cdot i d e v i_{i, t}$ is interacted with the dummies variables $u p_{i, t}$ and $d o w n_{i, t}$, which equal one when the trade occurred on a market up day or market down day, respectively. The p-values are included in parentheses.

\begin{tabular}{lcccc}
\hline & All & All & Up & Down \\
& Days & Days & Days & -28.548 \\
\hline I. idevi & -11.883 & -6.928 & -27.628 & $(0.000)$ \\
I. idevi. up & $(0.000)$ & $(0.000)$ & $(0.000)$ & \\
I. idevi · down & & -6.766 & & \\
spread & & $(0.000)$ & & \\
size & & -13.800 & & 0.053 \\
& 1.440 & $(0.000)$ & 8.550 & $(0.063)$ \\
depth & $(0.002)$ & 1.020 & $(0.483)$ & -4.236 \\
& -3.179 & $-2.008)$ & -4.158 & $-17.000)$ \\
vola & $(0.000)$ & $(0.000)$ & $(0.000)$ & $(0.000)$ \\
& -18.831 & -7.840 & -11.140 & 0.338 \\
vol & $(0.000)$ & $(0.000)$ & $(0.000)$ & $(0.000)$ \\
& -1.076 & -0.742 & 0.404 & -10.441 \\
& $(0.000)$ & $(0.000)$ & $(0.000)$ & $(0.000)$ \\
\hline
\end{tabular}




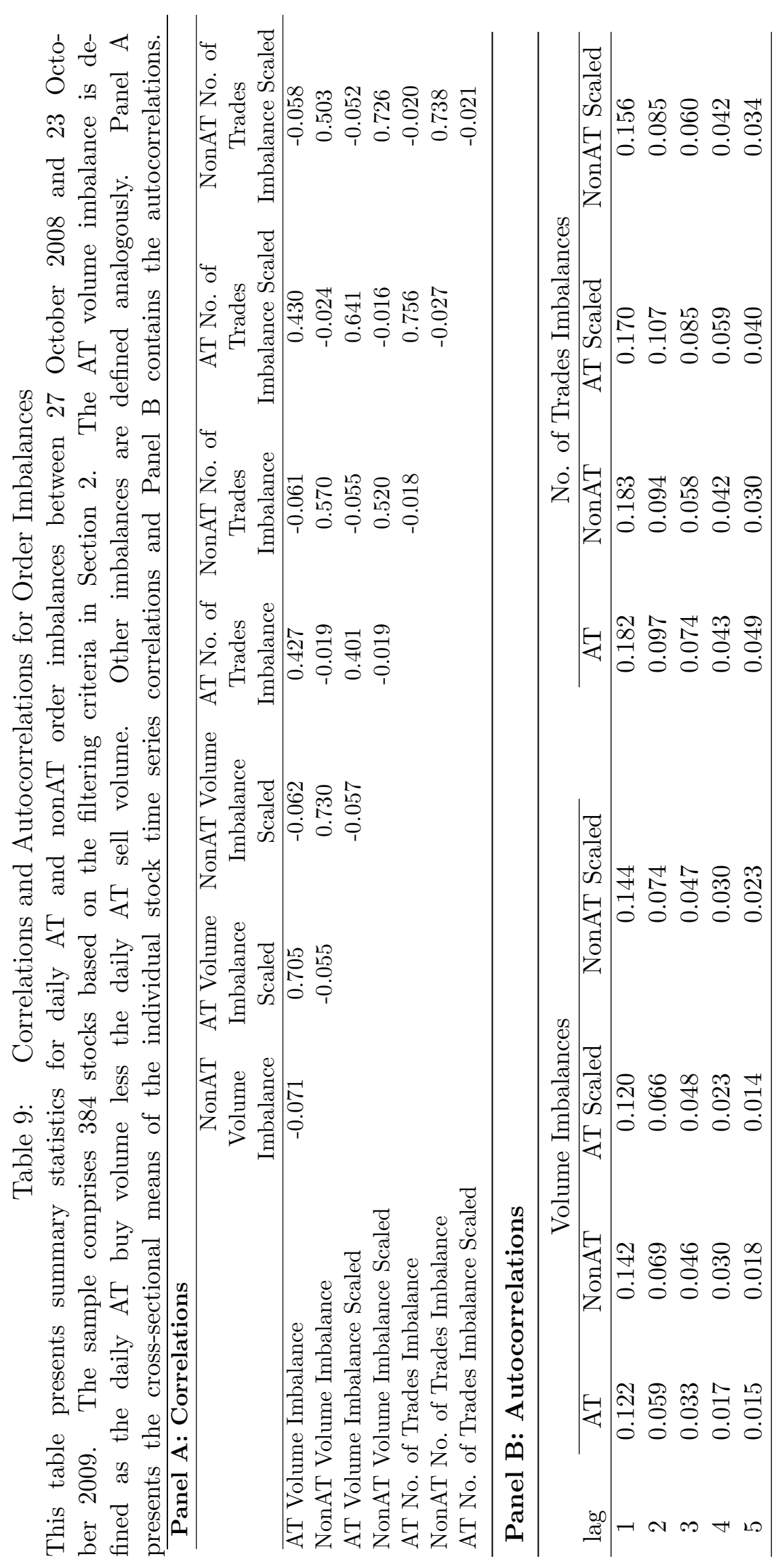


Table 10: $\quad$ Event-Day Market-Adjusted Return Regressions on Order Imbalances This table reports the coefficient estimates from Fama-MacBeth regressions using the following model:

$$
\begin{aligned}
\text { ar }_{i, t}= & \alpha+\beta_{1} \text { atoib }_{i, t}+\beta_{2} \text { nonatoib }_{i, t}+\sum_{k=1}^{4} \beta_{2+k} \text { atoib }_{i, t-k}+\sum_{k=1}^{4} \beta_{6+k} \text { nonatoib }_{i, t-k} \\
& +\beta_{11} \text { size }_{i, t}+\beta_{12} \text { turnover }_{i, t}+\beta_{13} \text { idiovar }_{i, t}+\beta_{14} \text { beta }_{i, t}+\epsilon_{i, t},
\end{aligned}
$$

where $a r_{i, t}$ is the market-adjusted abnormal return for stock $i$ on event day $t$. The event days are defined as the days when the absolute values of market returns exceed $2 \%$. In Panel $\mathrm{A}$, atoi $b_{i, t}$ is the order imbalance in the volume traded by $\mathrm{AT}$, nonatoib ${ }_{i, t}$ is the order imbalance in the volume traded by nonAT, size $_{i, t}$ is the logarithm of the market value of stock $i$ five days prior to event day $t$, turnover $_{i, t}$ is the ratio of the daily volume over the number of shares outstanding on event day $t$ for stock $i$, idiovar $r_{i, t}$ is the idiosyncratic variance of the market model residual of stock $i$ on days $[t-125, t-5]$, and beta $a_{i, t}$ is the beta of stock $i$ for days $[t-125, t-5]$. The p-values are reported from a t-test of the mean being different from zero. The event days are segregated into 19 up days and 20 down days. The coefficients for atoib $b_{i, t}$ and nonatoib $b_{i, t}$ are scaled by 100,000,000. In Panel B, atoib ${ }_{i, t}$ and nonatoib $_{i, t}$ are replaced by atoibscl $_{i, t}$ and nonatoibscl ${ }_{i, t}$, corresponding to order imbalance in the volume traded divided by the total volume for stock $i$ on event day $t$ for AT and nonAT, respectively. The coefficients for atoibscl $l_{i, t}$ and nonatoibscl $l_{i, t}$ are multiplied by 100 . The control variables are identical to

\begin{tabular}{|c|c|c|c|c|c|c|c|c|}
\hline & \multicolumn{4}{|c|}{ Up Days } & \multicolumn{4}{|c|}{ Down Days } \\
\hline & Mean & p-Value & Min & Max & Mean & p-Value & Min & Max \\
\hline \multicolumn{9}{|c|}{ Panel A: Volume Imbalance } \\
\hline atvoib & 1.43 & 0.001 & 0.12 & 5.22 & 1.28 & 0.000 & -0.33 & 4.87 \\
\hline natvoib & 2.13 & 0.000 & 0.25 & 8.15 & 2.53 & 0.000 & 0.42 & 7.76 \\
\hline beta & 1.71 & 0.000 & -0.02 & 4.52 & -1.79 & 0.000 & -4.34 & 0.65 \\
\hline turnover & 0.36 & 0.001 & -0.15 & 1.23 & -0.76 & 0.147 & -8.16 & 1.36 \\
\hline size & -0.55 & 0.590 & -6.50 & 9.75 & 0.25 & 0.701 & -4.25 & 7.99 \\
\hline idiovar & 0.49 & 0.307 & -3.57 & 4.42 & -0.01 & 0.984 & -4.72 & 4.78 \\
\hline \multicolumn{9}{|c|}{ Panel B: Volume Imbalance Scaled } \\
\hline atvoibs & 4.86 & 0.000 & 0.95 & 9.19 & 4.33 & 0.000 & 0.37 & 10.05 \\
\hline nstvoiba & 5.86 & 0.000 & 1.81 & 12.35 & 5.13 & 0.000 & 1.45 & 11.76 \\
\hline beta & 1.54 & 0.000 & -0.20 & 4.35 & -1.83 & 0.000 & -4.20 & 0.93 \\
\hline turnover & 0.52 & 0.001 & -0.58 & 1.55 & -0.37 & 0.209 & -3.16 & 2.78 \\
\hline size & -0.60 & 0.458 & -5.65 & 7.98 & -1.18 & 0.108 & -7.05 & 4.57 \\
\hline idiovar & 0.66 & 0.161 & -3.46 & 4.81 & -0.81 & 0.164 & -4.07 & 6.32 \\
\hline
\end{tabular}
those in Panel A. The coefficients for beta $a_{i, t}\left(\right.$ size $\left.i, t_{i}\right)$ are multiplied by $100(1,000)$. 
Table 11: Post-Event CARs

This table presents the results of post-event CAR analysis for stocks ranked by AT activity quartiles. The event days are defined as the days when the absolute values of market returns exceed 2\%. In Panel A, the CAR for stock $i$ is the market-adjusted return over five days after each event day. The CARs for individual stocks are partitioned into quartiles based on the AT buy (sell) volume market share on each up (down) day. The mean CAR difference between high- and low-AT stocks are presented. The p-values in parentheses correspond to a test of a null hypothesis that the CARs from high/low-AT quartiles have identical means. In Panel B, the CAR for stock $i$ is calculated as the five-day post-event return for stock $i$ less the mean five-day returns for all stocks in the same beta quartile as stock $i$ on the event day.

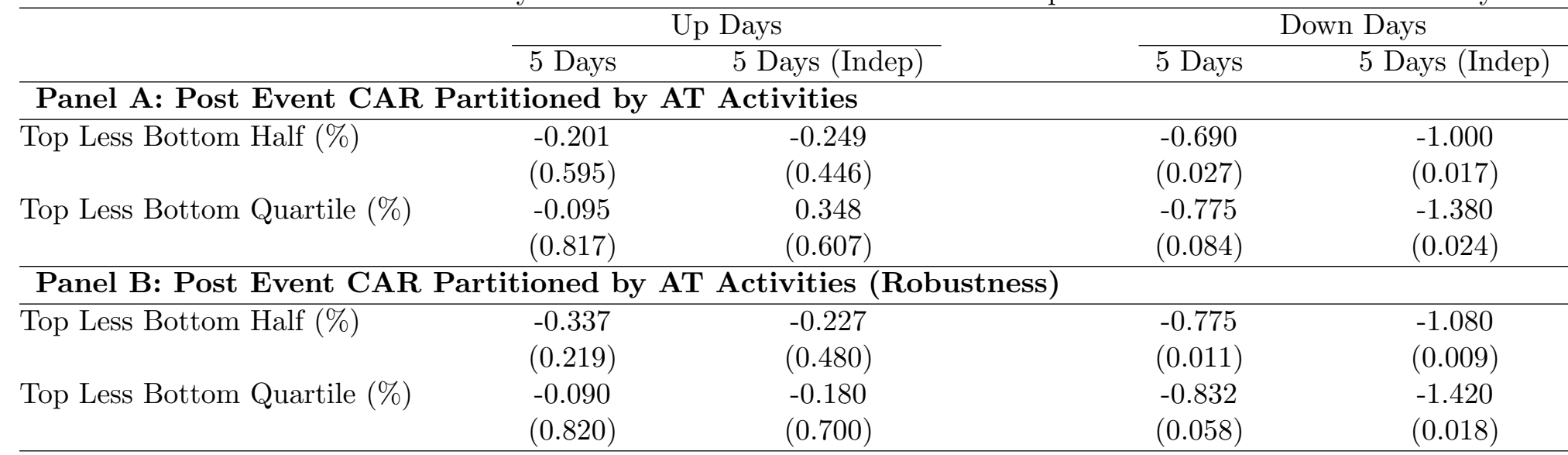




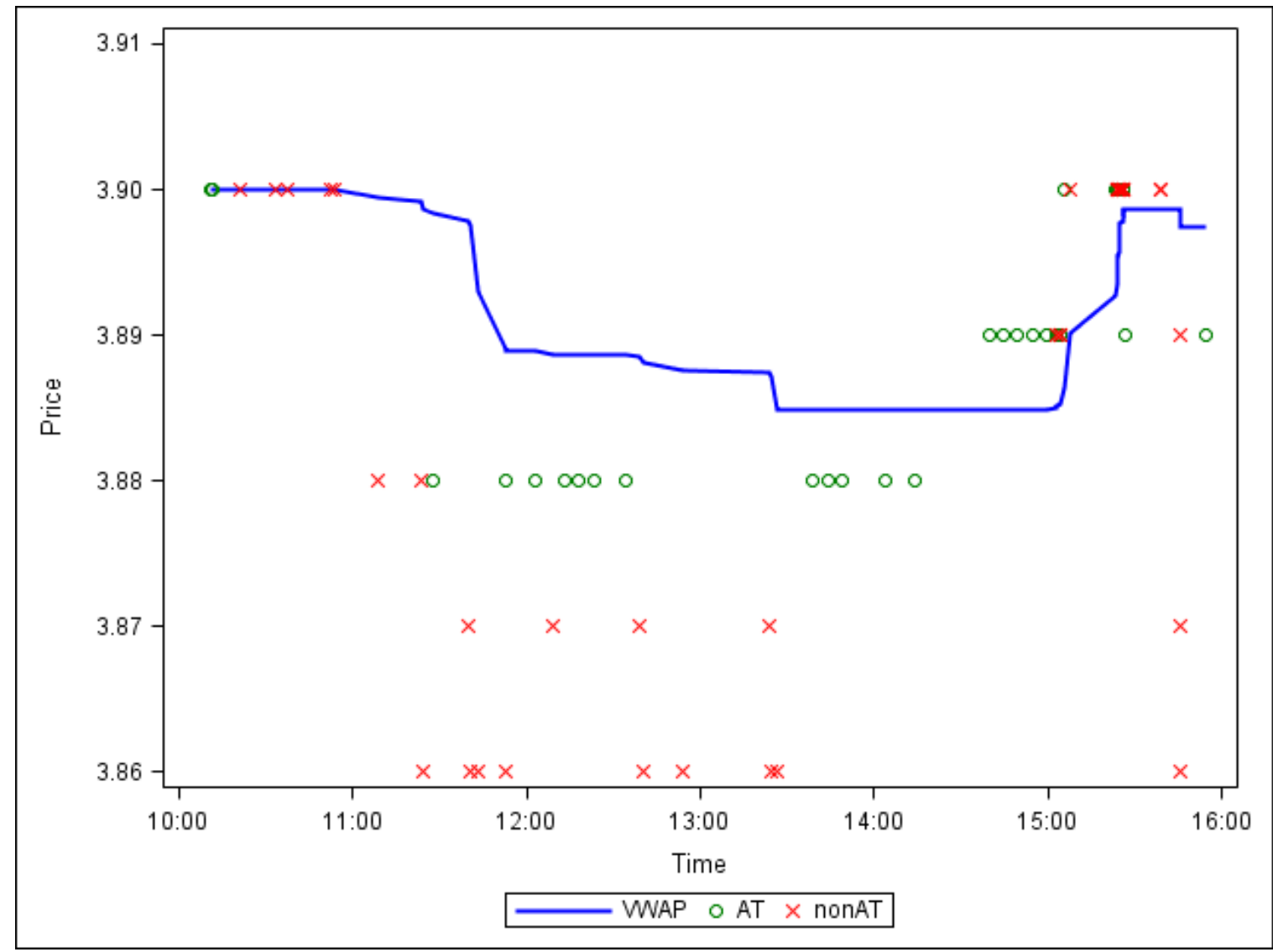

Fig. 1. The VWAP, AT, and NonAT of One Trading Session. This figure illustrates the intraday dynamics of the VWAP and AT and nonAT prices for the stock Premier Investments Limited (stock symbol PMV) on 4 August 2009. 